\title{
THE CHAOTIC GROWTH MODEL: INTERNATIONAL TOURISM
}

\author{
Vesna D. Jablanovic ${ }^{1}$ \\ DOI: https://doi.org/10.31410/tmt.2020.29
}

\begin{abstract}
The basic aims of this paper are: firstly, to create a relatively simple chaotic international tourism expenditure growth model that is capable of generating stable equilibria, cycles, or chaos; and secondly, to set up a relatively simple chaotic international tourism receipts growth model. This paper confirms stable growth of the international tourism receipts and expenditures in high-income countries, low \& middle-income countries, lower-middle-income countries, middle-income countries, and upper-middle-income countries in the period 1995-2018.
\end{abstract}

Keywords: Expenditure, Receipts, Tourism, Growth, Stability, Chaos.

\section{INTRODUCTION}

$\mathrm{T}$

ourism is one of the fastest-growing economic sectors. In 2018 tourism receipts amounted to $\$ 1,480$ billion, an increase of 4.4. percent. Tourism exports account for 7 percent of global trade in goods and services ( $\$ 1.7$ trillion). In 2019, the most popular destinations were France, Spain, the USA, and China. International tourism is among the economic sectors most impacted by the COVID-19 pandemic. The United Nations World Tourism Organization (UN WTO) estimates a loss of 850 million to 1.1 billion international tourist arrivals, $\$ 910$ million to $\$ 1.1$ trillion in export revenues, and 100-120 million jobs (UNCTAD, 2020, pg.7).

This paper uses the elements of chaos theory (Jablanovic, 2019). Also, this paper confirms stable growth of the international tourism receipts (as the ratio to exports of goods and services) and the international tourism expenditures (as the ratio to imports of goods and services) in high-income countries, low \& middle-income countries, lower-middle-income countries, middle-income countries, and upper-middle-income countries in the period 1995-2018.

\section{THE CHAOTIC INTERNATIONAL TOURISM EXPENDITURE GROWTH MODEL}

International tourism expenditures (E) are expenditures of international outbound visitors in other countries, including payments to foreign carriers for international transport. They may include those by residents traveling abroad as same-day visitors, except in cases where these are important enough to justify separate classification. Their share in imports (e) is calculated as a ratio to imports of goods and services (I), which comprise all transactions between residents of a country and the rest of the world involving a change of ownership from non-residents to residents of general merchandise, goods sent for processing and repairs, nonmonetary gold, and services (www.worldbank.org).

$$
e=E / I
$$

where:

$e$ - the ratio of international tourism expenditures $(E)$ to imports of goods and services $(I)$.

University of Belgrade, Faculty of Agriculture, Nemanjina 6, 11081 Belgrade, Serbia 
We index $e$ by $t$, i.e., write $e_{t}$ to refer to the size at time steps $t=0,1,2,3, \ldots$ Now the international tourism expenditures growth rate is measured by the quantity already given corresponding to the expression:

$$
\frac{e_{t+1}-e_{t}}{e_{t}}
$$

It is postulated that the growth rate of the ratio of international tourism expenditures (E) to imports of goods and services (I) at time $t$ should be proportional to $1-e_{t}$, after introducing a suitable parameter $\gamma$

$$
\frac{e_{t+1}-e_{t}}{e_{t}}=\gamma\left(1-e_{t}\right)
$$

Solving the last equation yields the growth model, i.e.,

$$
e_{t+1}=e_{t}+\gamma e_{t}\left(1-e_{t}\right)
$$

or,

$$
e_{t+1}=(1+\gamma) e_{t}-\gamma e_{t}^{2}
$$

This model given by equation (5) is called the logistic model. For most choices of $\gamma$, there is no explicit solution for (5). Namely, knowing $\gamma$ and measuring $e_{0}$ would not suffice to predict $e_{t}$ for any point in time, as was previously possible. Lorenz (1963) discovered this effect - the lack of predictability in deterministic systems. Sensitive dependence on initial conditions is one of the central ingredients of what is called deterministic chaos. This difference equation (5) will possess a chaotic region. Two properties of the chaotic solution are important: firstly, given a starting point $\mathrm{e}_{0}$ the solution is highly sensitive to variations of the parameter $\gamma$; secondly, given the parameter $\gamma$, the solution is highly sensitive to variations of the initial point $\mathrm{e}_{0}$. In both cases, the two solutions are for the first few periods rather close to each other, but later on, they behave chaotically.

It is possible to show that the iteration process for the logistic equation:

$$
z_{t+1}=\pi z_{t}\left(1-z_{t}\right), \pi \in[0,4], z_{t} \in[0,1]
$$

is equivalent to the iteration of the growth model (5) when we use the identification

$$
z_{t}=\frac{\gamma}{\gamma+1} e_{t}
$$

and

$$
\pi=1+\gamma
$$

Using (7) and (5) we obtain

$$
z_{t+1}=\frac{\gamma}{\gamma+1} e_{t+1}=\frac{\gamma}{\gamma+1}\left[(1+\gamma) e_{t}-\gamma e_{t}^{2}\right]=\gamma e_{t}-\frac{\gamma^{2}}{\gamma+1} e_{t}^{2}
$$


Using (6) and (7) we obtain

$$
z_{t+1}=\pi z_{t}\left(1-z_{t}\right)=(\gamma+1) \frac{\gamma}{\gamma+1}-e_{t}\left(1-\frac{\gamma}{\gamma+1} e_{t}\right)=\gamma e_{t}-\frac{\gamma^{2}}{\gamma+1} e_{t}^{2}
$$

Thus we have that iterating (5) is the same as iterating (6) using (7). It is important because the dynamic properties of the logistic equation (6) have been widely analyzed (Li and Yorke (1975), May (1976)).

It is obtained that :

- For parameter values $0<\pi<1$ all solutions will converge to $\mathrm{z}=0$;

- (ii) For $1<\pi<3,57$ there exist fixed points the number of which depends on $\pi$;

- (iii) For $1<\pi<2$ all solutions monotnically increase to $z=(\pi-1) / \pi$;

- (iv) For $2<\pi<3$ fluctuations will converge to $\mathrm{z}=(\pi-1) / \pi$;

- (v) For $3<\pi<4$ all solutions will continuously fluctuate;

- (vi) For 3,57 $<\pi<4$ the solution become ,chaotic“ which means that there exist aperiodic solution or periodic solutions with a very large, complicated period. This means that the path of $z_{t}$ fluctuates randomly over time, not settling down into any regular pattern whatsoever.

\section{EMPIRICAL EVIDENCE}

The main aim of this paper is to analyze the local growth stability of the ratio of international tourism expenditures (E) to imports of goods and services (I) in the period 1995-2018. in: high-income countries, low\&middle income countries, lower-middle-income countries, middle-income countries, and upper-middle-income countries (see Figures 1-5). In this sense, it is important to use the logistic model (8):

$$
e_{t+1}=\pi e_{t}-\gamma e_{t}^{2}
$$

where:

e - the international tourism expenditure (as the ratio to imports of goods and services),

$\pi-(1+\gamma), \gamma-$ the constant of proportionality.

Now, model (8) is estimated (see Tables 1-5).

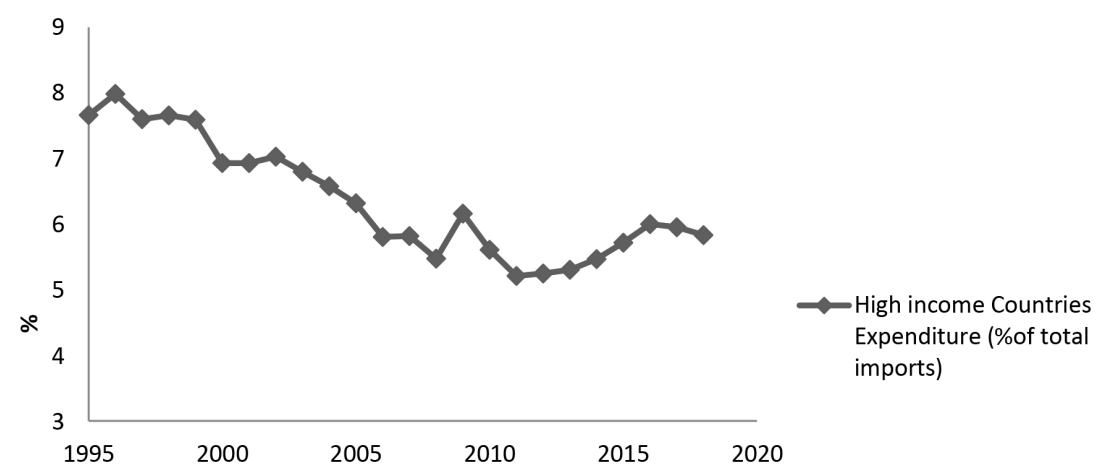

Figure 1. High-income countries, Expenditures (\% of total imports), 1995-2018.

Source: https://data.worldbank.org/indicator/ST.INT.XPND.MP.ZS?view=chart 
Table 1. The estimated model (8): High-income countries, 1995-2018

\begin{tabular}{|c|c|c|c|}
\hline \multirow{6}{*}{ 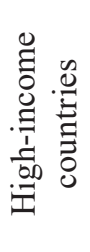 } & \multicolumn{3}{|c|}{$\mathrm{R}=0.93318$ Variance explained: $87.082 \%$} \\
\hline & & $\pi$ & $\gamma$ \\
\hline & Estimate & 1.06864 & 0.099957 \\
\hline & Std.Err. & 0.07663 & 0.091512 \\
\hline & $\mathbf{t}(21)$ & 13.94467 & 1.088348 \\
\hline & p-level & 0.00000 & 0.288775 \\
\hline
\end{tabular}

The expenditures moved from 7.6654 to 5.8421 (unit of measure: \% of total imports) in the period 1995-2018 in high-income countries. According to the logistic equation, for $1<\pi<2$ the expenditures moved to $\mathrm{z}=(\pi-1) / \pi$, or $(1.06864-1) / 1.06864=0.06423$. According to $(7$.$) , the$ equilibrium value of the expenditures was $0.06423 /(0.099957 / 1.06864)$ or $0.06423 / 0.09354$ or 0.68666 or 5.4858 (unit of measure: \% of total imports) in high-income countries in the observed period.

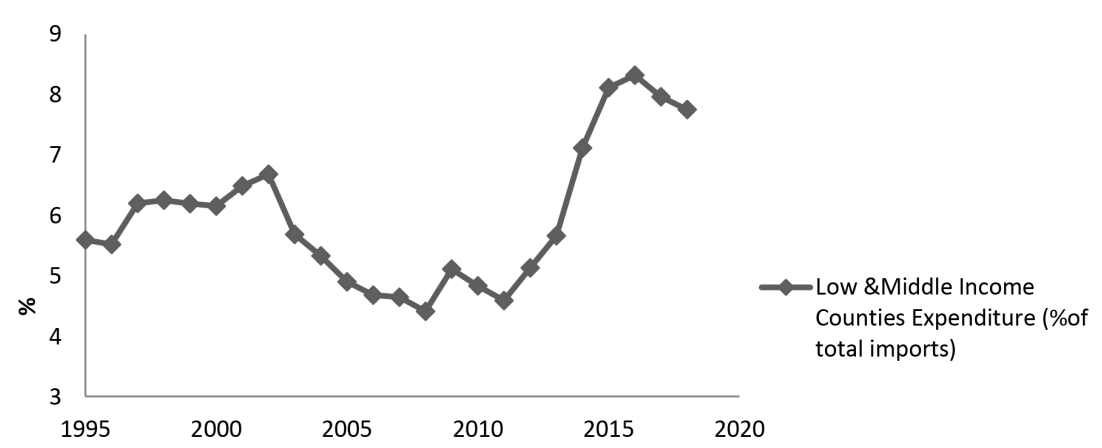

Figure 2. Low \& middle-income countries, Expenditures (\% of total imports)

Source: https://data.worldbank.org/indicator/ST.INT.XPND.MP.ZS?view=chart

Table 2. The estimated model (8): Low \& middle-income countries, 1995-2018.

\begin{tabular}{|c|c|c|c|}
\hline \multirow{6}{*}{ 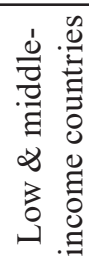 } & \multicolumn{3}{|c|}{$\mathrm{R}=0.89689$ Variance explained: $80.441 \%$} \\
\hline & & $\pi$ & $\gamma$ \\
\hline & Estimate & 1.08412 & 0.092879 \\
\hline & Std.Err. & 0.10069 & 0.129867 \\
\hline & $\mathbf{t}(21)$ & 10.76675 & 0.715185 \\
\hline & p-level & 0.00000 & 0.482371 \\
\hline
\end{tabular}

The expenditures moved from 5.6032 to 7.7564 (unit of measure: \% of total imports) in the period 1995-2018 in low \& middle income countries. According to the logistic equation, for $1<\pi<$ 2 the expenditures moved to $\mathrm{z}=(\pi-1) / \pi$, or $(1.08412-1) / 1.08412=0.0776$. According to (7.), the equilibrium value of the expenditures was $0.0776 /(0.092879 / 1.08412)$ or $0.0776 / 0.08567$ or 0.9058 or 7.5411 (unit of measure: \% of total imports) in low \& middle income countries in the observed period.

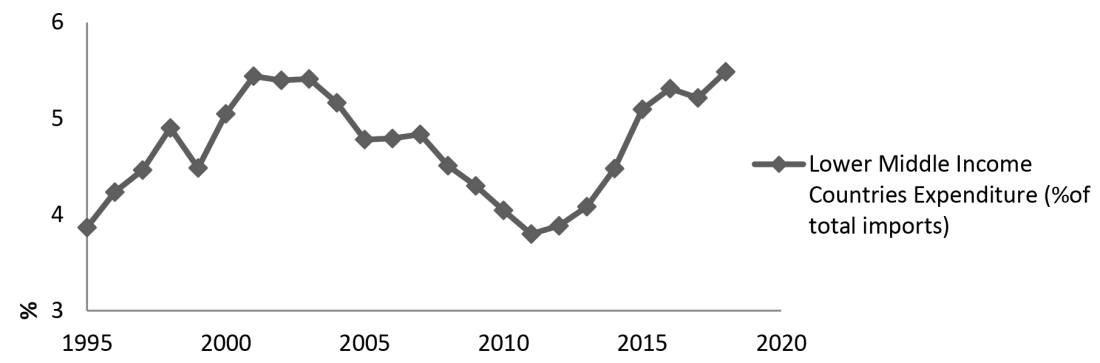

Figure 3. Lower middle-income countries, Expenditures (\% of total imports). 


\section{Source:https://data.worldbank.org/indicator/ST.INT.XPND.MP.ZS?view=chart}

Table 3. The estimated model (8): Lower middle-income countries, 1995-2018.

\begin{tabular}{|c|c|c|c|}
\hline \multirow{6}{*}{ 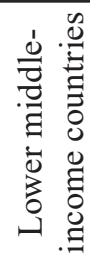 } & \multicolumn{3}{|c|}{$\mathrm{R}=0.831127$ Variance explained: $69.101 \%$} \\
\hline & & $\pi$ & $\gamma$ \\
\hline & Estimate & 1.217294 & 0.234344 \\
\hline & Std.Err. & 0.127489 & 0.145221 \\
\hline & $\mathbf{t}(21)$ & 9.548255 & 1.613702 \\
\hline & p-level & 0.00000 & 0.121519 \\
\hline
\end{tabular}

The expenditures moved from 3.8661 to 5.4868 (unit of measure: \% of total imports) in the period 1995-2018 in lower-middle-income countries. According to the logistic equation, for $1<\pi<2$ the expenditures moved to $\mathrm{z}=(\pi-1) / \pi$, or $(1.217294-1) / 1.217294=0.1785$. According to $(7$.$) , the$ equilibrium value of the expenditures was 0.1785 / (0.234344 / 1.217294) or 0.1785 / 0.1925 or 0.9273 or 5.0879 (unit of measure: \% of total imports) in lower-middle-income countries in the observed period.

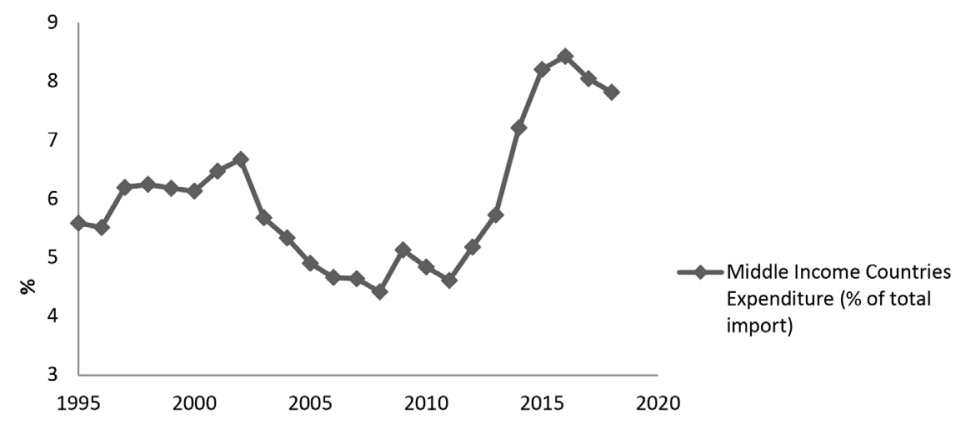

Figure 4. Middle-income countries, Expenditures (\% of total imports).

Source: https://data.worldbank.org/indicator/ST.INT.XPND.MP.ZS?view=chart

Table 4. The estimated model (8): Middle-income countries, 1995-2018.

\begin{tabular}{|c|c|c|c|}
\hline \multirow{6}{*}{ 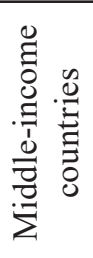 } & \multicolumn{3}{|c|}{$\mathrm{R}=0.89829$ Variance explained: $80.623 \%$} \\
\hline & & $\pi$ & $\gamma$ \\
\hline & Estimate & 1.07946 & 0.087817 \\
\hline & Std.Err. & 0.09972 & 0.129405 \\
\hline & t(21) & 10.82471 & 0.678620 \\
\hline & p-level & 0.00000 & 0.504789 \\
\hline
\end{tabular}

The expenditures moved from 5.5851 to 7.8151 (unit of measure: \% of total imports) in the period 1995-2018 in middle-income countries. According to the logistic equation, for $1<\pi<2$ the expenditures moved to $\mathrm{z}=(\pi-1) / \pi$, or $(1.07946-1) / 1.07946=0.0736$. According to $(7$.$) , the equi-$ librium value of the expenditures was 0.0736 / (0.087817 / 1.07946) or 0.0736 / 0.0814 or 0.9042 or 7.6189 (unit of measure: $\%$ of total imports) in middle-income countries in the observed period.

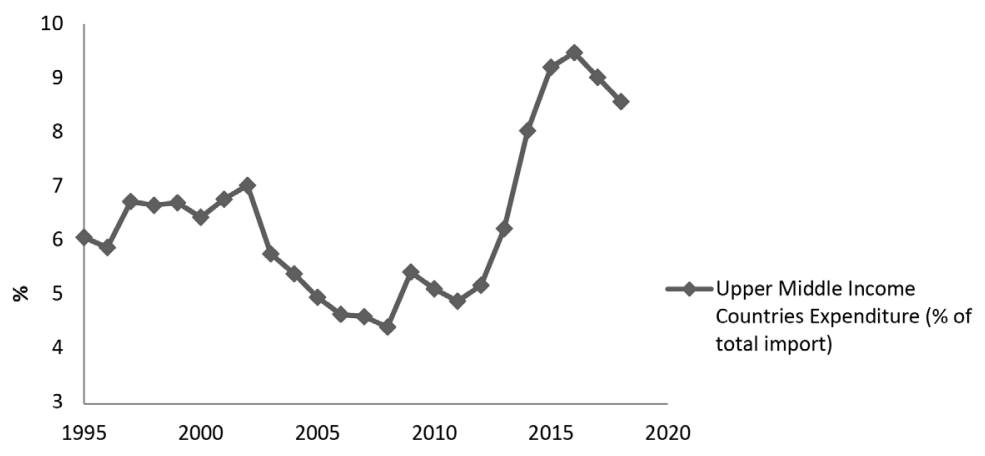


Figure 5. Upper middle-income countries, Expenditures (\% of total imports). Source:https://data.worldbank.org/indicator/ST.INT.XPND.MP.ZS?view=chart

Table 5. The estimated model (8): Upper middle-income countries, 1995-2018.

\begin{tabular}{|c|c|c|c|}
\hline \multirow{6}{*}{ 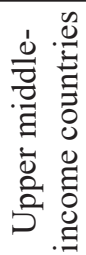 } & \multicolumn{3}{|c|}{$\mathrm{R}=0.46421$ Variance explained: $21.549 \%$} \\
\hline & & $\pi$ & $\gamma$ \\
\hline & Estimate & 1.144775 & 0.218628 \\
\hline & Std.Err. & 0.281749 & 0.367056 \\
\hline & $\mathbf{t}(\mathbf{2 1})$ & 4.063107 & 0.595627 \\
\hline & p-level & 0.000559 & 0.557790 \\
\hline
\end{tabular}

The expenditures moved from 6.0463 to 8.5599 (unit of measure: \% of total imports) in the period 1995-2018 in upper-middle-income countries. According to the logistic equation, for $1<\pi<2$ the expenditures moved to $\mathrm{z}=(\pi-1) / \pi$, or $(1.144775-1) / 1.144775=0.1265$. According to (7.), the equilibrium value of the expenditures was $0.1265 /(0.218628 / 1.144775)$ or 0.1265 / 0.191 or 0.6623 or 6.2701 (unit of measure: \% of total imports) in upper-middle-income countries in the observed period.

\section{THE CHAOTIC INTERNATIONAL TOURISM RECEIPTS GROWTH MODEL}

International tourism receipts $(\mathrm{R})$ are expenditures by international inbound visitors, including payments to national carriers for international transport. They include any other prepayment made for goods or services received in the destination country. They also may include receipts from same-day visitors, except when these are important enough to justify separate classification. Their share in exports ( $r$ ) is calculated as a ratio to exports of goods and services (E), which comprise all transactions between residents of a country and the rest of the world involving a change of ownership from residents to nonresidents of general merchandise, goods sent for processing and repairs, nonmonetary gold, and services (www.worldbank.org).

$$
R=R / E
$$

We index $r$ by $t$, i.e., write $r_{t}$ to refer to the size at time steps $t=0,1,2,3, \ldots$ Now the growth rate is measured by the quantity already given corresponding to the expression:

$$
\frac{r_{t+1}-r_{t}}{r_{t}}
$$

It is postulated that the growth rate of the ratio $(\mathrm{r})$ between international tourism receipts and exports at time $t$ should be proportional to $1-\mathrm{r}_{\mathrm{t}}$, after introducing a suitable parameter $\delta$, i.e.,

$$
\frac{r_{t+1}-r_{t}}{r_{t}}=\delta\left(1-r_{t}\right)
$$

Solving the last equation yields the unemployment rate growth model, i.e.,

$$
r_{t+1}=r_{t}+\delta r_{t}\left(1-r_{t}\right)
$$

or

$$
r_{t+1}=(1+\delta) r_{t}-\delta r_{t}^{2}
$$


This model given by equation (13) is called the logistic model. For most choices of $\delta$, there is no explicit solution for (13). This difference equation (13) will possess a chaotic region.

Also, it is possible to show that iteration process for the logistic equation:

$$
z_{t+1}=\pi z_{t}\left(1-z_{t}\right), \pi \in[0,4], z_{t} \in[0,1]
$$

is equivalent to the iteration of the growth model (13) when we use the identification

$$
z_{t}=\frac{\delta}{1+\delta} r_{t} \text { and } \pi=1+\delta
$$

Using (13) and (14) we obtain:

$$
z_{t+1}=\frac{\delta}{1+\delta} r_{t+1}=\frac{\delta}{1+\delta}\left[(1+\delta) r_{t}-\delta r_{t}^{2}\right]=\delta r_{t}-\frac{\delta^{2}}{1+\delta} r_{t}^{2}
$$

Using (6) and (14) we obtain:

$$
z_{t+1}=\pi z_{t}\left(1-z_{t}\right)=(1+\delta) \frac{\delta}{1+\delta} r_{t}\left(1-\frac{\delta}{1+\delta} r_{t}\right)=\delta r_{t}-\frac{\delta^{2}}{1+\delta} r_{t}^{2}
$$

Thus we have that iterating (13) is the same as iterating (6) using (14).

\section{EMPIRICAL EVIDENCE}

The main aim of this paper is to analyze the local growth stability of the ratio of international tourism receipts (R) to exports of goods and services (E) in the period 1995-2018. in: high-income countries, low \& middle-income countries, lower-middle-income countries, middle-income countries, and upper-middle-income countries (see Figures 6-10). In this sense, it is important to use the logistic model (15):

$$
r_{t+1}=\pi r_{t}-\delta e_{t}^{2}
$$

where:

$\mathrm{r}$ - the international tourism receipts (as the ratio to exports of goods and services), $\pi-(1+\delta), \delta$ - the constant of proportionality.

Now, the model (15) is estimated (see Tables 6-10.).

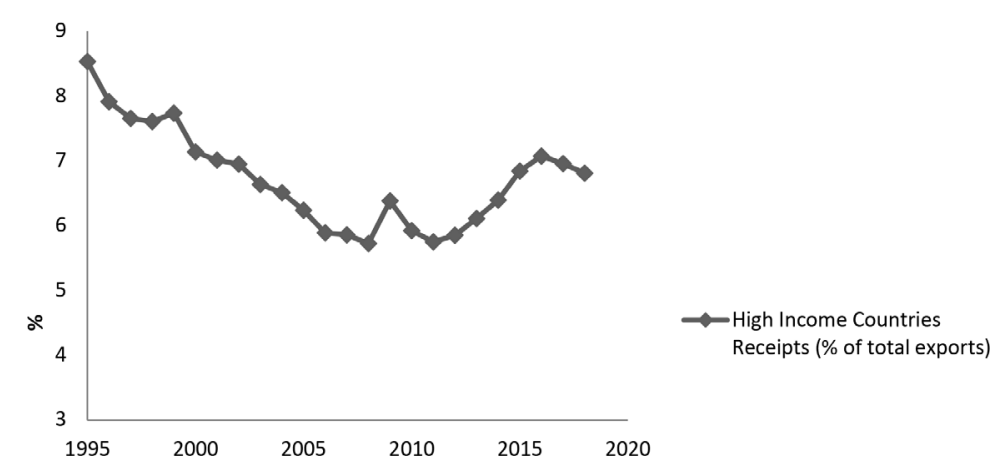

Figure 6. High-income countries, Receipts (\% of total exports).

Source: https://data.worldbank.org/indicator/ST.INT.RCPT.XP.ZS?view=chart 
Table 6. The estimated model (15): High-income countries, 1995-2018.

\begin{tabular}{|c|c|c|c|}
\hline \multirow{6}{*}{ 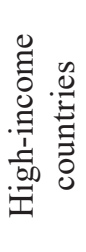 } & \multicolumn{3}{|c|}{$\mathrm{R}=0.91797$ Variance explained: $84.268 \%$} \\
\hline & & $\pi$ & $\gamma$ \\
\hline & Estimate & 1.17528 & 0.233532 \\
\hline & Std.Err. & 0.17395 & 0.090804 \\
\hline & $t(21)$ & 15.89264 & 2.571812 \\
\hline & p-level & 0.00000 & 0.017778 \\
\hline
\end{tabular}

The receipts moved between 6.0463 and 8.5266 (unit of measure: \% of total exports) in the period 1995-2018 in high-income countries. According to the logistic equation, for $1<\pi<2$ the receipts moved to $\mathrm{z}=(\pi-1) / \pi$, or $(1.17528-1) / 1.17528=0.1491$. According to $(14$.$) , the equilibrium$ value of the expenditures was $0.1491 /(0.233532$ / 1.17528) or $0.1491 / 0.1987$ or 0.7504 or 6.3984 (unit of measure: \% of total exports) in high-income countries in the observed period.

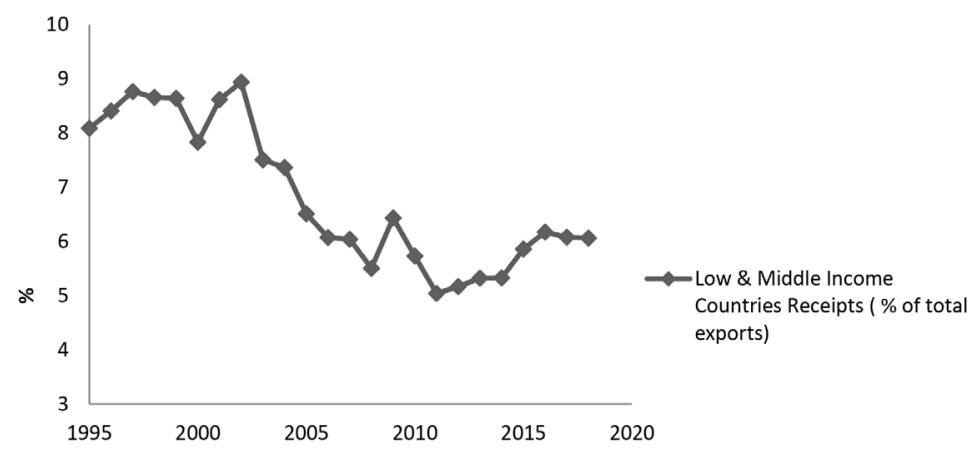

Figure 7. Low \& middle-income countries, Receipts (\% of total exports).

Source: https://data.worldbank.org/indicator/ST.INT.RCPT.XP.ZS?view=chart

Table 7. The estimated model (15): Low \& middle-income countries, 1995-2018.

\begin{tabular}{|c|c|c|c|}
\hline \multirow{6}{*}{ 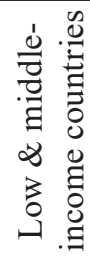 } & \multicolumn{3}{|c|}{$\mathrm{R}=0.91255$ Variance explained: $83.275 \%$} \\
\hline & & $\pi$ & $\gamma$ \\
\hline & Estimate & 1.06888 & 0.102672 \\
\hline & Std.Err. & 0.09616 & 0.114700 \\
\hline & $\mathbf{t}(21)$ & 11.11570 & 0.895135 \\
\hline & p-level & 0.00000 & 0.380861 \\
\hline
\end{tabular}

The receipts moved from 8.0903 to 6.0655 (unit of measure: \% of total exports) in the period 19952018 in low \& middle income countries. According to the logistic equation, for $1<\pi<2$ the receipts moved to $\mathrm{z}=(\pi-1) / \pi$, or $(1.06888-1) / 1.06888=0.0644$. According to (14.), the equilibrium value of the expenditures was $0.0644 /(0.102672 / 1.06888)$ or $0.0644 / 0.0961$ or 0.6701 or 5.9928 (unit of measure: \% of total exports) in low \& middle income countries in the observed period.

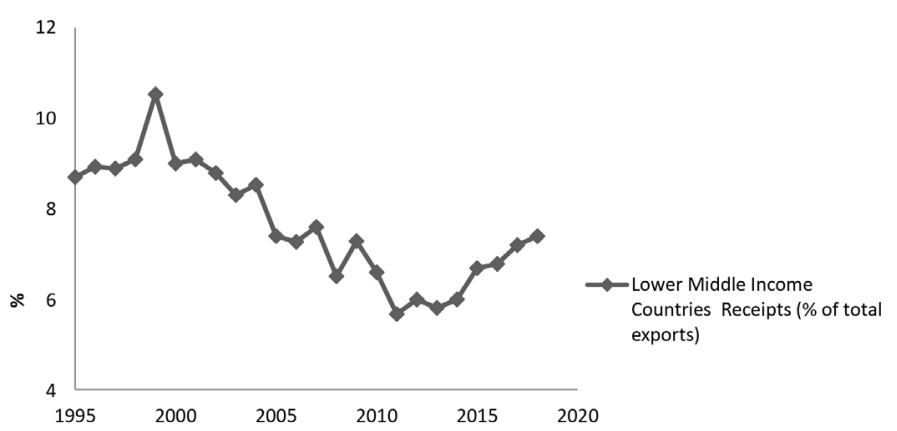

Figure 8. Lower middle-income countries, Receipts (\% of total exports).

Source: https://data.worldbank.org/indicator/ST.INT.RCPT.XP.ZS?view=chart 
Table 8. The estimated model (15): Lower middle-income countries, 1995-2018.

\begin{tabular}{|c|c|c|c|}
\hline \multirow{6}{*}{ 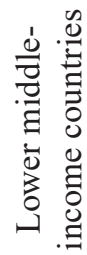 } & \multicolumn{3}{|c|}{$\mathrm{R}=0.86711$ Variance explained: $75.188 \%$} \\
\hline & & $\pi$ & $\gamma$ \\
\hline & Estimate & 1.14345 & 0.200432 \\
\hline & Std.Err. & 0.11413 & 0.146230 \\
\hline & $\mathbf{t}(21)$ & 10.01858 & 1.370659 \\
\hline & p-level & 0.00000 & 0.184955 \\
\hline
\end{tabular}

The receipts moved from 8.7120 to 7.4149 (unit of measure: \% of total exports) in the period 19952018 in lower-middle-income countries. According to the logistic equation, for $1<\pi<2$ the receipts moved to $\mathrm{z}=(\pi-1) / \pi$, or $(1.14345-1) / 1.14345=0.1255$. According to $(14)$, the equilibrium value of the expenditures was 0.1255 / (0.200432/1.14345) or 0.1255 / 0.1753 or 0.7159 or 7.5422 (unit of measure: \% of total exports) in lower middle-income countries in the observed period.

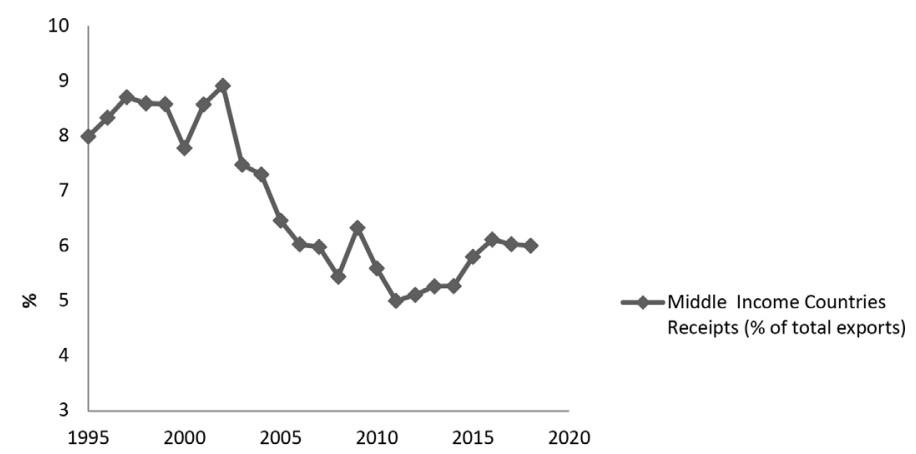

Figure 9. Middle-income countries, Receipts (\% of total exports).

Source: https://data.worldbank.org/indicator/ST.INT.RCPT.XP.ZS?view=chart

Table 9. The estimated model (15): Middle-income countries, 1995-2018.

\begin{tabular}{|c|c|c|c|}
\hline \multirow{6}{*}{ 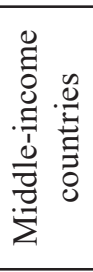 } & \multicolumn{3}{|c|}{$\mathrm{R}=0.47489$ Variance explained: $22.552 \%$} \\
\hline & & $\pi$ & $\gamma$ \\
\hline & Estimate & 1.06727 & 0.101047 \\
\hline & \begin{tabular}{|l|} 
Std.Err. \\
\end{tabular} & 0.09536 & 0.114224 \\
\hline & $t(21)$ & 11.19247 & 0.884637 \\
\hline & p-level & 0.00000 & 0.386370 \\
\hline
\end{tabular}

The receipts moved from 7.9876 and 5.9977 (unit of measure: \% of total exports) in the period 1995-2018 in middle income countries. According to the logistic equation, for $1<\pi<2$ the receipts moved to $\mathrm{z}=(\pi-1) / \pi$, or $(1.06727-1) / 1.06727=0.063$. According to (14), the equilibrium value of the expenditures was 0.063 / $(0.101047$ / 1.06727) or 0.063 / 0.0947 or 0.6653 or 5.927 (unit of measure: \% of total exports) in middle-income countries in the observed period.

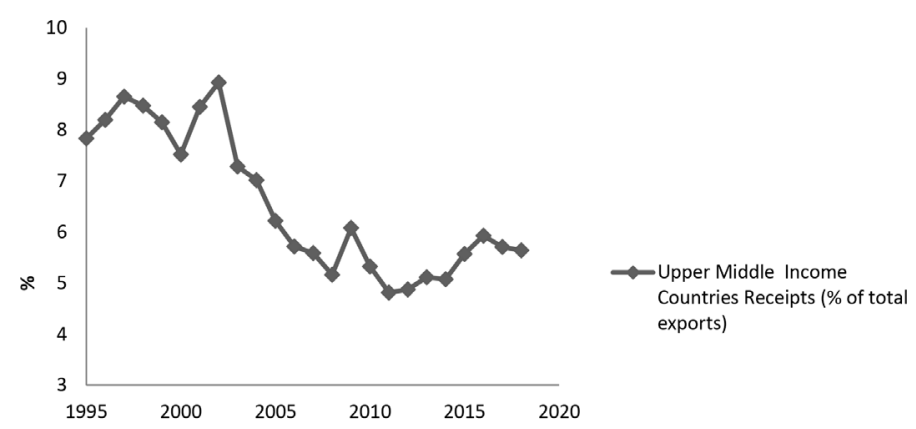

Figure 10. Upper middle-income countries, Receipts (\% of total exports).

Source: https://data.worldbank.org/indicator/ST.INT.RCPT.XP.ZS?view=chart 
Table 10. The estimated model (15): Upper-middle-income countries, 1995-2018.

\begin{tabular}{|c|c|c|c|}
\hline \multirow{6}{*}{ 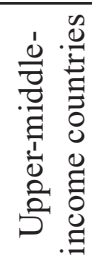 } & \multicolumn{3}{|c|}{$\mathrm{R}=0.90943$ Variance explained: $82.707 \%$} \\
\hline & & $\pi$ & $\gamma$ \\
\hline & Estimate & 1.07053 & 0.110353 \\
\hline & Std.Err. & 0.09825 & 0.120360 \\
\hline & $t(21)$ & 10.89623 & 0.916863 \\
\hline & p-level & 0.00000 & 0.369624 \\
\hline
\end{tabular}

The receipts moved from 7.8344 to 5.6439 (unit of measure: \% of total exports) in the period 1995-2018 in upper middle-income countries. According to the logistic equation, for $1<\pi<$ 2 the receipts moved to $z=(\pi-1) / \pi$, or $(1.07053-1) / 1.07053=0.0659$. According to (14), the equilibrium value of the expenditures was 0.0659 / (0.110353 / 1.07053) or $0.0659 / 0.1031$ or 0.6392 or 5.7091 (unit of measure: \% of total exports) in upper middle-income countries.

\section{CONCLUSION}

This paper confirms the stable movement of the international tourism expenditure (as the ratio to imports of goods and services), in high-income countries, low \& middle-income countries, lower-middle-income countries, middle-income countries, and upper-middle-income countries in the period 1995-2018.

Also, this paper confirms the stable movement of the international tourism receipts (as the ratio to exports of goods and services) in high-income countries, low \& middle-income countries, lower-middle-income countries, middle-income countries, and upper-middle-income countries in the period 1995-2018.

\section{REFERENCES}

Benhabib, J., Day, R.H. (1981) Rational Choice and Erratic Behaviour, Review of Economic Studies 48: 459-471.

Benhabib, J., Day, R.H. (1982) Characterization of Erratic Dynamics in the Overlapping Generation Model. Journal of Economic Dynamics and Control 4: 37-55.

Day, R.H. (1982) Irregular Growth Cycles. American Economic Review 72: 406-414.

Day, R.H. (1983) The Emergence of Chaos from Classica Economic Growth. Quarterly Journal of Economics 98: 200-213.

Day, R.H. (1997) Complex Economic Dynamics. Volume I: "An introduction to dynamical systems and market mechanism", MIT Press, In: Discrete Dynamics in Nature and Society, Vol. 1. 177-178.

Goodwin, R.M. (1990) Chaotic Economic Dynamics. Clarendon Press, Oxford.

Grandmont, J.M. (1985) On Endogenous Competitive Business Cycles. Econometrica 53: 994-1045.

Jablanovic, V. (2019) The Chaotic Growth Model of the Total Consumption Visitor Expenditure: Euro Area. 4th International Thematic Monograph Modern management tools and of economy of tourism sector in present era. pp. 17-31, Association of Economists and Managers of the Balkans in cooperation with the Faculty of Tourism and Hospitality, Ohrid, North Macedonia, ISBN 978-8680194-29-5, DOI https://doi.org/10.31410/tmt.2019.17

Medio, A. (1996) Chaotic dynamics. Theory and applications to economics. Cambridge University Press, In: De Economist 144 (4), 695-698. Covid-19 and Tourism: Assessing the Economic Consequences (2020) United Nations Conference on Trade and Development. https://unctad.org/system/files/official-document/ditcinf2020d3 en.pdfhttps://data.worldbank.org/indicator/ST.INT. RCPT.XP.ZS?view $=$ chart 